\title{
Fluid management in infants and children during intracranial surgery
}

\author{
Hemangi S. Karnik
}

\begin{abstract}
Fluid management in neurosurgical paediatric patients can be a real challenge due to their different pathophysiology, sensitivity to fluid loss, inability to accurately judge the degree of abnormality and adequacy of replacement in face of limited monitoring. For infants and children undergoing neurosurgical procedures, isotonic fluids should be used for maintenance and replacement to avoid increase in intracranial pressure and maintain cerebral perfusion. Routine use of added dextrose is not needed, but blood glucose monitoring should be done in high risk population. Preoperative deficits and intraoperative blood loss should be closely monitored and treated. Hyponataemia and other electrolyte derangements are common and should be monitored.
\end{abstract}

Key words: Children, intravenous fluids, neurosurgery

\section{INTRODUCTION}

Fluid management in surgical patient is an important aspect of perioperative care. In case of infants and children, it can be a real challenge due to their different pathophysiology, sensitivity to fluid loss, inability to accurately judge the degree of abnormality and adequacy of replacement in the face of limited monitoring. Although there are many guidelines available for paediatric population, most of them do not take into consideration rapidly changing perioperative volume status. In addition, neurosurgical condition itself predisposes the patient to many fluid and electrolyte disturbances secondary to diuretic therapy, pre-existing deficits, diabetes insipidus (DI) or other disturbances.

Department of Anaesthesiology, LTM Medical College and General Hospital, Mumbai, Maharashtra, India

Address for correspondence:

Dr. Hemangi S. Karnik, N-2/3, Narayan Pujari Nagar,

Khan Abdul Gafar Khan Road, Worli, Mumbai - 400 018,

Maharashtra, India.

E-mail: dr_hemangi@hotmail.com

\begin{tabular}{|l|l|}
\hline \multicolumn{2}{|c|}{ Access this article online } \\
\hline Quick Response Code: & Website: \\
\hline & www.jnaccjournal.org \\
\hline & \\
\hline & \\
\hline
\end{tabular}

\section{DEVELOPMENTAL CHANGES IN FLUID PHYSIOLOGY}

From a neonatal age to adult, there is a gradual reduction in total body water from $75 \%$ to $80 \%$ in newborn to $60 \%$ in adults. ${ }^{[1]}$ In first few days after birth, interstitial fluid is absorbed and excreted resulting in reduction of $5 \%-10 \%$ body weight. ${ }^{[2]}$ The blood volume also reduces from 85 to $90 \mathrm{ml} / \mathrm{kg}$ in a full-term neonate, $80 \mathrm{ml} / \mathrm{kg}$ in 2-year-old baby and $75-80 \mathrm{ml} / \mathrm{kg}$ in children and adolescents. ${ }^{[3]}$

In infants and neonates, there is increased capillary permeability to proteins, making them prone for oedema formation. Insensible water loss through immature skin is high in neonates. ${ }^{[4]}$ Infants and neonates also have very low renal blood flow, glomerular filtration rate and urine concentration ability resulting in dilute urine. Inability to excrete sodium or water load makes neonates prone for volume overload and oedema. Immature kidney in infants and neonates also shows decreased

This is an open access article distributed under the terms of the Creative Commons Attribution-NonCommercial-ShareAlike 3.0 License, which allows others to remix, tweak, and build upon the work non-commercially, as long as the author is credited and the new creations are licensed under the identical terms.

For reprints contact: reprints@medknow.com

How to cite this article: Karnik HS. Fluid management in infants and children during intracranial surgery. J Neuroanaesthesiol Crit Care 2017;4:S24-9. 
responsiveness to hormones involved in regulation of fluid and electrolyte balance. ${ }^{[4,5]}$

Infants and children have higher resting heart rate. Hence, there is limited capacity to further increase the heart rate to increase cardiac output in response to hypovolaemia. Bradycardia, on the other hand, can drastically reduce the cardiac output.

\section{TYPES OF FLUIDS AND THEIR EFFECTS ON BRAIN}

The presence of blood-brain barrier (BBB) prevents movements of proteins and small ions like sodium, potassium and chloride across it. Total osmotic gradient determines the fluid movement across BBB. Even a small reduction in osmolality will increase the brain water content and produce oedema ${ }^{[6]}$ In the presence of intracranial tumour, traumatic brain injury or convulsions the response may be variable depending upon the integrity of BBB. Disrupted BBB will allow free passage of molecules. ${ }^{[7]}$

\section{Crystalloids}

Electrolyte requirements in children can be met by hypoosmolar fluids like dextrose $5 \%$ in water, Isolyte $\mathrm{P}$ or $0.45 \% \mathrm{NaCl}$ in children, but the use of hypotonic solutions along with stress induced increased secretion of antidiuretic hormone (ADH) perioperatively can lead to hyponatraemia. ${ }^{[1]}$ Administration of hypoosmolar fluids also results in movement of water across BBB into brain tissue and cause cerebral oedema. Iso-osmolar fluids like $0.9 \% \mathrm{NaCl}(300 \mathrm{Osm} / \mathrm{L})$ or balanced salt solution like plasmalyte (294 mOsmol/L) maintain the osmotic gradient across BBB and hence are preferred maintenance fluids. ${ }^{[8,9]}$ Ringers lactate solution, though used as isotonic fluid, has slightly lower osmolality ( $275 \mathrm{mOsm} / \mathrm{L}$ ) as compared to plasma and may increase brain oedema.

Hyperosmolar fluid like $20 \%$ mannitol or $3 \% \mathrm{NaCl}$ will draw water from brain tissue. Various studies have shown that hypertonic saline solutions lower intracranial pressure (ICP) and improve cerebral perfusion pressure. ${ }^{[10]}$

\section{Colloids}

Colloids retain water in the intravascular compartment for longer duration, and lesser volumes are needed as compared to crystalloids. Administration of human albumin 5\% has been associated with lesser degree of cerebral oedema than isotonic crystalloids following traumatic brain injury. ${ }^{[11]}$ However, it is expensive and does not offer any advantage over synthetic colloids such as tetrastarches and gelatines. Albumin and hydroxyethyl starch 130/0.42 may produce weaker clot in neurosurgical patients, and hence monitoring of coagulation during their use has been advocated. ${ }^{[12,13]}$ These effects are clinically insignificant if infused volume is $<25 \%$ of the patient's blood volume. ${ }^{[1]}$ Tetrastarch in balanced salt solution (e.g., Volulyte, Tetraspan) offer some advantage in preserving renal function and are considered safe in infants and children. ${ }^{[14]}$ Use of gelatine is associated with hypersensitivity reactions and worsening capillary leak syndrome.

\section{PRE-OPERATIVE ORAL FLUID MANAGEMENT}

- Clear liquids can be given $2 \mathrm{~h}$ before surgery or breast milk $4 \mathrm{~h}$ before surgery in infants and children without increasing risk of pulmonary aspiration. Formula feeds, milk or solid enteral feeds should be withheld for $6 \mathrm{~h}$ before surgery

- In neurosurgical patients with decreased levels of consciousness, loss of protective airway reflexes, delay in surgical timings or in the presence of vomiting enteral fluids may have to be withheld for longer duration. Intravenous fluids should be started to maintain fluid balance in such cases.

\section{INTRAOPERATIVE FLUID MANAGEMENT}

Intraoperative goal of fluid management during neurosurgery is to maintain normovolaemia with normal or slightly increased serum osmolarity. A delicate balance needs to be maintained using right volume of right kind of fluid considering the cerebral perfusion, cerebral oedema, water and sodium balance and glucose concentration. ${ }^{[15]}$

Any perioperative fluid management plan has following three main components.

\section{Pre-existing deficit}

Many of the paediatric patients coming for neurosurgical procedures have pre-existing fluid deficit. The many possible reasons include overstarvation, vomiting, diuretic therapy, cerebrospinal fluid (CSF) loss in the presence of ventricular drainage, DI, etc.

It is extremely important to identify fluid and electrolyte deficits prior to surgery and correct as much as possible to prevent perioperative haemodynamic instability and inadequate tissue perfusion. The degree of deficit can be judged by clinical signs [Table 1].

The type of deficit should be determined by serum osmolarity and serum electrolytes. The fluid deficit should be corrected with $10-20 \mathrm{ml} / \mathrm{kg}$ fluid boluses of isotonic crystalloids for children above 1 month of age. In case of anaemia, blood transfusion may be needed. Restoration of an adequate intravascular volume is 
Table 1: Assessment of fluid deficit

\begin{tabular}{llll}
\hline Degree of fluid deficit & Mild (5\%) & Moderate (10\%) & Severe (15\%) \\
\hline $\begin{array}{l}\text { Clinical signs and } \\
\text { symptoms }\end{array}$ & $\begin{array}{l}\text { Increased thirst, dry } \\
\text { mucous membranes }\end{array}$ & $\begin{array}{l}\text { Tachypnoea, decreased skin turgor, } \\
\text { cool, peripheries with increased } \\
\text { capillary refill time, sunken eyes }\end{array}$ & $\begin{array}{l}\text { Irritability, lethargy, deep } \\
\text { breathing, sunken fontanelle, } \\
\text { acidosis, hypotension }\end{array}$ \\
\hline
\end{tabular}

necessary to maintain cardiovascular stability and adequate tissue perfusion. ${ }^{[1]}$

\section{Maintenance fluids}

Maintenance fluids requirements in infants and children older than 4 weeks are calculated based on Holliday and Segar formula [Table 2]. ${ }^{[16]}$

Hours of starvation are included in this calculation. Maintenance fluids calculated plus remaining deficits should be given over $3 \mathrm{~h}$ with $50 \%$ administered in the first hour. Isotonic fluids like $0.9 \%$ sodium chloride or Ringer's lactate solution are recommended as maintenance therapy in the absence of other concomitant electrolyte disturbances. Large amount of $0.9 \% \mathrm{NaCl}$ may produce hyperchloraemic metabolic acidosis, and large volume of Ringer's lactate may increase cerebral oedema, hence, both of these should be avoided. Alternating both solution is also recommended. ${ }^{[15]}$ Currently, it is recommended that intraoperative fluid in neonates, infants and children should have an osmolarity close to the physiological range to avoid hyponatraemia, an addition of $1 \%-2.5 \%$ glucose to avoid hypoglycaemia, if required and preferably should also include metabolic anions such as acetate, lactate or malate to prevent hyperchloraemic acidosis especially in neonates. ${ }^{[1]}$

Higher volume of fluids is needed in the presence of fever and hypermetabolic states.

Following precautions must be taken during fluid management in infants and children:

- Remove all air bubbles from syringes and infusion sets

- Calculate volumes accurately using burette set or syringes

- Consider non-calculated fluid administration and blood or fluid loss during drug administrations and blood sampling

- Warm intravenous fluids to body temperature before administering.

\section{Assessment of blood loss and replacement}

In addition to correction of fluid deficit and providing maintenance fluids, the anaesthesiologist needs to consider intraoperative losses due to blood loss, CSF loss, urine output and insensible losses. Exact amount of blood loss is difficult to measure as most of the loss occurs in the drapes which may not be easily seen by anaesthesiologist. Hence, intraoperative estimation of haematocrit is needed
Table 2: Holliday and Segar Formula

\begin{tabular}{lc}
\hline Body weight $\mathbf{( k g )}$ & Daily fluid requirement \\
\hline $0-10$ & $4 \mathrm{ml} / \mathrm{kg} / \mathrm{h}$ \\
$10-20$ & $40 \mathrm{ml} / \mathrm{h}+2 \mathrm{ml} / \mathrm{kg} / \mathrm{h}$ above $10 \mathrm{~kg}$ \\
$>20$ & $60 \mathrm{ml} / \mathrm{h}+1 \mathrm{ml} / \mathrm{kg} / \mathrm{h}$ above $20 \mathrm{~kg}$ \\
\hline
\end{tabular}

when large blood loss is expected. The blood loss up to $10 \%-15 \%$ blood volume may be replaced with isotonic crystalloids, and additional blood loss should be replaced with packed red cells if haematocrit falls below 25. It is advisable to start the blood replacement early during the surgery than wait till major blood loss. Colloids like tetrastarch or gelatine are used for volume replacement if blood products are not readily available.

\section{Dextrose management during surgery}

The majority of children may be given fluids without dextrose in the intraoperative period without risk of hypoglycaemia during neurosurgery. ${ }^{[17]}$ However, blood glucose should be monitored and hypoglycaemia should be avoided especially in smaller children on long-term intravenous fluids, diabetic children, neonates and malnourished children. Hyperglycaemia can aggravate ischaemic brain injury and blood glucose $>250 \mathrm{mg} \%$ should be avoided. Magnoni et al. have proved that in injured brain glucose levels can go below critical levels even when systemic glucose levels are in lower normal range. ${ }^{[18]}$ Therefore, it is advisable to keep blood glucose levels in higher range $140-180 \mathrm{mg} \%$ in children undergoing neurosurgical procedures.

\section{Role of osmotherapy}

Administration of mannitol may produce transient but profound hypotension followed by increase in circulatory blood volume and cardiac index for about $30 \mathrm{~min}$. In case of large lesions or severe traumatic injury cerebral oedema may worsen due to deranged BBB. Mannitol in dosages of $0.5-1 \mathrm{~g} / \mathrm{kg}$ may be used intravenously, 6 hourly with monitoring of serum osmolality. It should not be used if serum osmolality is $>330$, patient is hypotensive or in patients with renal failure. ${ }^{[19]}$

Hypertonic saline solutions $(3 \%, 7.5 \%$ or $10 \%)$ are used as cerebral dehydrating agent or to correct hyponatraemia. They do not produce diuresis and hence hypotension is not observed. Use of hypertonic saline significantly reduces the risk of tight brain during neurosurgey. ${ }^{[7]}$ 
A single bolus has a time-limited effect and a risk of rebound of intracranial hypertension, whereas continuous therapy with hypertonic saline can produce hypernatremia, central pontine myelinolysis or renal failure. ${ }^{[20-22]}$

\section{POST-OPERATIVE FLUID MANAGEMENT}

Surgery, post-operative pain, vomiting and shivering are all potent causes of ADH release in the post-operative period. Hence, it has been recommended that hypotonic fluids should not be used as post-operative maintenance fluids as this may cause hyponatraemia. Ringer's lactate or balanced salt solution with added dextrose if needed are preferred fluids for maintenance in post-operative phase. On-going blood loss may need to be replaced by blood products. Other losses through surgical drains and nasogastric tube should be regularly measured and replaced with an isotonic fluid like $0.9 \%$ sodium chloride with or without potassium supplementation.

Intravenous fluids should be continued till oral intake approximates maintenance rate. All fluid intakes-oral and parenteral-should be recorded on a fluid balance chart.

\section{MONITORING FLUID THERAPY}

While managing the fluid therapy, monitoring of both adequacy and appropriateness of type of fluid is essential.

- Body weight: All children should be weighed before starting the fluid therapy. Post-operatively regular monitoring of weight helps in assessing the hydration status

- Heart rate and blood pressure: Though tachycardia is most common and early sign of fluid deficit, it is not specific, especially in intraoperative period and is only used as a guide to response to therapy. Roughly following minimum systolic blood pressure targets are used in children with an arterial line:

- $\quad$ Age $\leq 10$ years $>60-70 \mathrm{mmHg}$

- Age $>10$ years $>70-80 \mathrm{mmHg}$.

- Hypotension is a late sign of hypovolaemia and normal blood pressure does not rule out volume deficit

- Central venous pressure (CVP): CVP monitoring is indicated for major surgeries with large fluid shifts and patients with cardiac diseases. Rather than absolute value, trends in CVP should be used to guide fluid therapy

- Pulse pressure variation (PPV): Major surgeries with expected large blood loss requires arterial line placement. Arterial waveform with minimal respiratory variation and good amplitude of dicrotic notch suggests good cardiac output. However, PPV and other dynamic variables may not predict fluid responsiveness in children ${ }^{[23]}$

- Urine output: Urine output above $1 \mathrm{ml} / \mathrm{kg}$ in the absence of diuretic therapy suggests adequate renal perfusion

- Blood glucose and electrolyte monitoring: Serum electrolytes and blood glucose should be monitored preoperatively and at least daily after surgery, till the child is on intravenous therapy.

\section{SPECIFIC SITUATIONS}

\section{Hyponatremia}

Hyponatremia (serum $\mathrm{Na}<135 \mathrm{mmol} / \mathrm{L}$ ) may occur during or following surgery, secondary to syndrome of inappropriate antidiuretic hormone secretion (SIADH), cerebral salt wasting and overzealous fluid resuscitation, especially if hypotonic maintenance fluids are given. It may be a cause of delayed return of consciousness and hyponatraemic seizures respond poorly to anticonvulsants. Symptomatic children can be treated with infusion of $3 \%$ sodium chloride solution. One $\mathrm{ml} / \mathrm{kg}$ of $3 \% \mathrm{NaCl}$ will increase the serum sodium by $1 \mathrm{mmol} / \mathrm{L}$. The amount of $\mathrm{Na}$ supplementation needed can be calculated with the following formula:

mmol of Na required $=(130-$ present serum $\mathrm{Na}) \times$ $0.6 \times$ weight $(\mathrm{kg})$.

Rapid administration of $3 \%$ or $7.5 \% \mathrm{NaCl}$ can produce central pontine myelinolysis. Therefore, the rate of correction should not exceed $0.5 \mathrm{mEq} / \mathrm{h} .{ }^{[24]}$

If hyponatremia is due to SIADH fluid restriction may be required. In case of cerebral salt wasting syndrome, normal or hypertonic saline infusion is needed to treat hypovolaemia with hyponatraemia.

\section{Hypernatraemia}

In neurosurgical patients, hypernatraemia (serum $\mathrm{Na}>150 \mathrm{mmol} / \mathrm{L}$ ) commonly occurs following multiple doses of mannitol or hypertonic saline (3\% sodium chloride). Intravascular volume may be preserved in the early stages but dehydration if present, needs to be rapidly corrected. The serum $\mathrm{Na}$ can be corrected with $0.45 \%$ sodium chloride with or without dextrose at a rate of no more than $12 \mathrm{mmol} / \mathrm{kg} /$ day. Potassium should only be added to maintenance fluids once urine output is established.

\section{Craniopharyngioma/diabetes Insipidus}

In patients undergoing craniopharyngioma or other sellar or supracellar surgeries, possibility of DI occurring secondary to ADH deficiency is high either during or after surgery. The main clinical features are 
polyuria ( $>5 \mathrm{ml} / \mathrm{kg} / \mathrm{h}$ ), dehydration, hypernatremia and increased plasma osmolality $(>300 \mathrm{mOsm} / \mathrm{kg}) \cdot{ }^{[25]}$ Close monitoring and recording of fluid balance is needed to avoid fluid overload or electrolyte imbalance. Intraoperative use of normal saline is associated with higher incidence of hypernartaemia and DI. ${ }^{[26]}$ Frequent check on serum osmolality helps to guides the volume and type of fluid to be administered. A common regimen is to give maintenance fluids plus three-quarter of the previous hour's urine output using a fluid with a low sodium load like $0.45 \% \mathrm{NaCl}$ or dextrose $5 \%$ in water.

\section{Hydrocephalus}

In congenital hydrocephalus, large amount of CSF contributes significantly to total body weight. This affects the calculation of fluid management based on weight basis. Approximate reduction in doses should be done while calculating fluid volume for replacement. All patients with external ventricular drainage will have sodium loss and should have pre-operative serum electrolyte levels checked.

During endoscopic third ventriculostomy procedure for congenital hydrocephalus, post-operative hypokalaemia is seen, due to disturbances in hypothalamic nuclei in the floor of the third ventricle. ${ }^{[27]}$ However, irrigation of Ringer's lactate solution has also been associated with instances of hyperkalaemia. ${ }^{[28]}$ Use of $0.9 \% \mathrm{NaCl}$ for irrigation may produce an inflammatory response and CSF acidosis. ${ }^{[29,30]}$ Therefore, it is recommended to use $0.9 \% \mathrm{NaCl}$ for intravenous fluid replacement and a warm Ringer's lactate solution for ventricular irrigation. ${ }^{[31]}$

\section{Head injury}

Following head injury, infants are more susceptible to large subdural haematomas and cortical and subcortical tears due to expandable skull, lack of glial tissue and movable squamosal bones. After myelinisation begins at the first year, contusions, subarachnoid and epidural haematoma and diffuse axonal injuries are more commonly seen. ${ }^{[19]}$ Even large scalp lacerations in infants and small children can cause significant blood loss necessitating resuscitation. Following a head injury, acute hypoperfusion of brain with vasogenic and cytotoxic oedema may develop rapidly. Associated other system injury aggravates the anaemia and hypotension.

The preferred fluid in a head injured child should be one which maintains circulating blood volume without causing cerebral oedema. Isotonic saline is recommended as preferred fluid to start the therapy. In hypotensive trauma patients, hypertonic saline solutions can restore normovolaemia rapidly and reduce cerebral oedema without increasing the ICP. ${ }^{[32]}$

Both mannitol and hypertonic saline solutions have been used to treat intracranial hypertension in paediatric head trauma patients. Administration of hypertonic saline solutions decreases ICP without rebound rise, improved cerebral perfusion and restored cerebral oxygenation. ${ }^{[20,33]}$ Brain Trauma Foundation 2012 guidelines recommend the use of both bolus therapy $3 \%$ saline and continuous infusion 3\% saline for treatment of intracranial hypertension in paediatric patients. ${ }^{[33]}$ Although central pontine myelinolysis is not seen in head injury patients, its possibility should be kept in mind and caution must be exerted. ${ }^{[11,20]}$ Head injury may also cause DI, which should be identified, monitored and treated as described earlier.

\section{Craniofacial surgeries}

Craniofacial surgeries are often prolonged procedures involving large blood loss, typically done in infants and small children. Fluid management significantly contributes to the success of these surgeries. There can be extensive blood loss and third space fluid loss from the scalp and the cranium and therefore at least two large indwelling cannulas should be secured, one for maintenance fluids and drugs and another for rapid fluid and blood replacement. Replacement of deficit and maintenance fluid management is as per the general paediatric protocol.

The estimation of blood loss is difficult due to loss on the drapes and fluid irrigation. Early fluid replacement is generally done with Ringer's lactate solution in 3:1 ratio ${ }^{[34]}$ Colloids are usually used only after $50 \mathrm{ml} / \mathrm{kg}$ of crystalloids have been given especially when single unit blood transfusion is to be avoided. Intraoperative haemoglobin or haematocrit estimations are needed to judge the adequacy of blood replacement with packed red cells. In case of loss of a large blood volume fresh frozen plasma and platelet transfusion are required to prevent abnormalities of coagulation. Blood loss can be reduced using judicious use of infiltration with vasopressors, meticulous surgical technique and avoiding dilutional coagulopathies. ${ }^{[35]}$

\section{CONCLUSION}

For infants and children undergoing neurosurgical procedures, isotonic fluids should be used for maintenance and replacement to avoid an increase in ICP and maintain cerebral perfusion. Routine use of added dextrose is not needed, but blood glucose monitoring should be done in high-risk population. Pre-operative deficits and intraoperative blood loss should be closely monitored and treated. Hyponatremia and other electrolyte derangements are common and should be monitored.

\section{Financial support and sponsorship} Nil. 


\section{Conflicts of interest}

There are no conflicts of interest.

\section{REFERENCES}

1. Arya VK. Basics of fluid and blood transfusion therapy in paediatric surgical patients. Indian J Anaesth 2012;56:454-62.

2. Friis-Hansen B. Water distribution in the foetus and newborn infant. Acta Paediatr Scand Suppl 1983;305:7-11.

3. Brett $C$, Char D. Fluids, electrolytes and nutrition. In: Gregory GA, Andropoulos DB, editors. Gregory's Pediatric Anesthesia. $5^{\text {th }}$ ed. UK: Wiley and Blackwell; 2012. p. 205-23.

4. Malde AD. Perioperative fluid and electrolyte therapy. In: Dhayagude SH, Dave NM, editors. Principles and Practice of Pediatric Anesthesia. New Delhi: Jaypee Brothers; 2016. p. 120-34.

5. Sulyok E, Kovács L, Lichardus B, Michajlovskij N, Lehotska V, Némethova $\mathrm{V}$, et al. Late hyponatremia in premature infants: Role of aldosterone and arginine vasopressin. J Pediatr 1985;106:990-4.

6. Drummond JC, Patel PM, Cole DJ, Kelly PJ. The effect of the reduction of colloid oncotic pressure, with and without reduction of osmolality, on post-traumatic cerebral edema. Anesthesiology 1998;88:993-1002.

7. Ali Z, Prabhakar H. Fluid management during neurosurgical procedures. J Neuroanaesth Crit Care 2016;3 Suppl S1:S35-40.

8. Allen $\mathrm{CH}$, Goldman RD, Bhatt S, Simon HK, Gorelick MH, Spandorfer PR, et al. A randomized trial of Plasma-Lyte A and $0.9 \%$ sodium chloride in acute pediatric gastroenteritis. BMC Pediatr 2016;16:117.

9. Houghton J, Wilton N. Choice of isotonic perioperative fluid in children. Anesth Analg 2011;112:246-7.

10. Gunnar W, Jonasson O, Merlotti G, Stone J, Barrett J. Head injury and hemorrhagic shock: Studies of the blood brain barrier and intracranial pressure after resuscitation with normal saline solution, 3\% saline solution, and dextran-40. Surgery 1988;103:398-407.

11. Singh P. Intravenous fluid considerations in the resuscitation of a head injured patient. Indian J Neurotrauma 2005;2:87-90.

12. Nilsson $\mathrm{CU}$, Strandberg $K$, Engström $M$, Reinstrup $P$. Coagulation during elective neurosurgery with hydroxyethyl starch fluid therapy: An observational study with thromboelastometry, fibrinogen and factor XIII. Perioper Med (Lond) 2016;5:20.

13. Li N, Statkevicius S, Asgeirsson B, Schött U. Effects of different colloid infusions on ROTEM and multiplate during elective brain tumour neurosurgery. Perioper Med (Lond) 2015;4:9.

14. Sümpelmann R, Kretz FJ, Luntzer R, de Leeuw TG, Mixa V, Gäbler R, et al. Hydroxyethyl starch 130/0.42/6:1 for perioperative plasma volume replacement in 1130 children: Results of an European prospective multicenter observational postauthorization safety study (PASS). Paediatr Anaesth 2012;22:371-8.

15. McClain CD, Soriano SG, Rockoff MA. Pediatric neurosurgical anesthesia. In: Coté CJ, Lerman J, Todres ID, editors. A Practice of Anesthesia for Infants and Children. $4^{\text {th }}$ ed. Philadelphia, PA: Saunders Elsevier; 2009. p. 509-34.

16. Holliday MA, Segar WE. The maintenance need for water in parenteral fluid therapy. Pediatrics 1957;19:823-32.

17. Rath GP, Dash HH. Anaesthesia for neurosurgical procedures in paediatric patients. Indian J Anaesth 2012;56:502-10.
18. Magnoni S, Tedesco C, Carbonara M, Pluderi M, Colombo A, Stocchetti N. Relationship between systemic glucose and cerebral glucose is preserved in patients with severe traumatic brain injury, but glucose delivery to the brain may become limited when oxidative metabolism is impaired: Implications for glycemic control. Crit Care Med 2012;40:1785-91.

19. Khilnani P. Management of pediatric head injury. Indian J Crit Care Med 2004;8:85-92.

20. Roquilly A, Mahe PJ, Latte DD, Loutrel O, Champin P, Di Falco C, et al. Continuous controlled-infusion of hypertonic saline solution in traumatic brain-injured patients: A 9-year retrospective study. Crit Care 2011;15:R260.

21. Lien YH, Shapiro JI, Chan L. Study of brain electrolytes and organic osmolytes during correction of chronic hyponatremia. Implications for the pathogenesis of central pontine myelinolysis. J Clin Invest 1991;88:303-9.

22. Huang PP, Stucky FS, Dimick AR, Treat RC, Bessey PQ, Rue LW. Hypertonic sodium resuscitation is associated with renal failure and death. Ann Surg 1995;221:543-54.

23. Gan H, Cannesson M, Chandler JR, Ansermino JM. Predicting fluid responsiveness in children: A systematic review. Anesth Analg 2013;117:1380-92.

24. Meyers RS. Pediatric fluid and electrolyte therapy. J Pediatr Pharmacol Ther 2009;14:204-11.

25. Agha A, Sherlock M, Phillips J, Tormey W, Thompson CJ. The natural history of post-traumatic neurohypophysial dysfunction. Eur J Endocrinol 2005;152:371-7.

26. Mukherjee KK, Dutta P, Singh A, Gupta P, Srinivasan A, Bhagat H, et al. Choice of fluid therapy in patients of craniopharyngioma in the perioperative period: A hospital-based preliminary study. Surg Neurol Int 2014;5:105.

27. El-Dawlatly AA. Blood biochemistry following endoscopic third ventriculostomy. Minim Invasive Neurosurg 2004;47:47-8.

28. Nerurkar AA, Virkar ND, Shastri S, Karnik HS. A study of haemodynamic and electrolyte changes during neuroendoscopic procedures under general anaesthesia. Indian J Appl Res 2016;6:192-6.

29. Oka K, Yamamoto $M$, Nonaka $T$, Tomonaga $M$. The significance of artificial cerebrospinal fluid as perfusate and endoneurosurgery. Neurosurgery 1996;38:733-6.

30. Emory L, Schubert A. Awake craniotomy, epilepsy, minimally invasive and robotic surgery. In: Cottrell JE, Patel P, editors. Cottrell and Patel's Neuroanesthesia. Edinburgh: Elsevier; 2017. p. 298-316.

31. Derbent A, Erşahin Y, Yurtseven T, Turhan T. Hemodynamic and electrolyte changes in patients undergoing neuroendoscopic procedures. Childs Nerv Syst 2006;22:253-7.

32. Mazzoni MC, Borgström $\mathrm{P}$, Arfors $\mathrm{KE}$, Intaglietta $\mathrm{M}$. Dynamic fluid redistribution in hyperosmotic resuscitation of hypovolemic hemorrhage. Am J Physiol 1988;255(3 Pt 2):H629-37.

33. Kochanek PM, Carney N, Adelson PD, Ashwal S, Bell MJ, Bratton S, et al. Guidelines for the acute medical management of severe traumatic brain injury in infants, children, and adolescents - Second edition. Pediatr Crit Care Med 2012;13 Suppl 1:S1-82.

34. Zunini GS, Rando KA, Cox RG. Fluid replacement in craniofacial pediatric surgery: Normal saline or ringer's lactate? J Craniofac Surg 2011;22:1370-4

35. Bajwa SS, Kulshrestha A. Craniofacial and maxillary anomalies: Anesthetic implications and management. J Sci Soc 2014;41:73-8. 